\title{
Characteristics of Effective Teaching in Physician Assistant Programs from the Students' Perspective
}

Jennifer Forbes

University of Utah, jennifer.forbes@utah.edu

Talia Sierra

Idaho State University

Jane Trapp

East Carolina University

Thomas Parish

Eastern Virginia Medical School

Follow this and additional works at: https://nsuworks.nova.edu/ijahsp

Part of the Medicine and Health Sciences Commons

\section{Recommended Citation}

Forbes J, Sierra T, Trapp J, Parish T. Characteristics of Effective Teaching in Physician Assistant Programs from the Students' Perspective. The Internet Journal of Allied Health Sciences and Practice. 2018 Jan 01;16(3), Article 3.

This Manuscript is brought to you for free and open access by the College of Health Care Sciences at NSUWorks. It has been accepted for inclusion in Internet Journal of Allied Health Sciences and Practice by an authorized editor of NSUWorks. For more information, please contact nsuworks@nova.edu. 


\title{
Characteristics of Effective Teaching in Physician Assistant Programs from the Students' Perspective
}

\begin{abstract}
Purpose: This qualitative study aims to identify the characteristics physician assistant (PA) students find most important for effective teaching by faculty in physician assistant programs. With this information, physician assistant faculty can enhance their teaching effectiveness in the classroom and optimize the environment for student learning. Faculty may also use the data obtained from this study to increase the likelihood of their retention or promotion as student input regarding teaching effectiveness is frequently one of the variables used in faculty evaluations.

Methods: Physician assistant students from three physician assistant programs were emailed a survey that asked for their response to an open-ended question: "What are the most important qualities or characteristics for physician assistant faculty to possess for effective teaching in a physician assistant program?" The responses were categorized using Marsh's Students' Evaluation of Educational Quality framework.

Results: Respondents most frequently listed individual words or phrases that corresponded to the categories of individual rapport and organization.

Conclusions: Physician assistant faculty who possess good individual rapport and organizational skills are more likely to be viewed as effective teachers by physician assistant students. Faculty that are lacking those skills could enhance their teaching effectiveness and the opportunity for advancement in their physician assistant program by improving their individual rapport with students and their organizational skills.
\end{abstract}

\section{Author Bio(s)}

Jennifer Forbes, MHS, PA-C, is an Assistant Professor of Physician Assistant Studies at the University of Utah. She was an Assistant Professor of Physician Assistant Studies at Idaho State University at the time the research was conducted.

Talia Sierra, MPAS, PA-C, is an Assistant Professor of Physician Assistant Studies at Idaho State University. Jane Trapp, MS Ed, PA-C, is a Clinical Associate Professor of Physician Assistant Studies at East Carolina University.

Thomas Parish, DHSc, PA-C, DFAAPA, is a Professor of Physician Assistant Studies at Eastern Virginia Medical School. 


\title{
TUAHSP" \\ The Internet Joưnal of Allied Health Sciences and Practice \\ Dedicated to allied health professional practice and education
}

Vol. 16 No. 3 ISSN 1540-580X

\section{Characteristics of Effective Teaching in Physician Assistant Programs from the Students' Perspective}

\author{
Jennifer Forbes, MHS, PA-C1 \\ Talia Sierra, MPAS, PA-C2 \\ Jane Trapp, MS Ed, PA-C ${ }^{3}$ \\ Thomas Parish, DHSc, PA-C, DFAAPA 4 \\ 1. University of Utah \\ 2. Idaho State University \\ 3. East Carolina University \\ 4. Eastern Virginia Medical School \\ United States
}

\begin{abstract}
Purpose: The purpose of this qualitative study was to identify the characteristics physician assistant (PA) students find most important for effective teaching by faculty in PA programs. With this information, PA faculty members can enhance their teaching effectiveness in the classroom and optimize the environment for student learning. Faculty members may also use the data obtained from this study to increase the likelihood of their retention or promotion as student input regarding teaching effectiveness is frequently one of the variables used in faculty evaluations. Methods: PA students from 3 physician assistant programs were emailed a survey in which their response to an open-ended question was solicited: "What are the most important qualities or characteristics for physician assistant faculty to possess for effective teaching in a physician assistant program?" The responses were categorized using Marsh's Students' Evaluation of Educational Quality framework. Results: Respondents most frequently listed individual words or phrases that corresponded to the categories of individual rapport and organization. Conclusions: PA faculty members who possess good individual rapport and organizational skills are more likely to be viewed as effective teachers by PA students. Faculty members who are lacking those skills could enhance their teaching effectiveness and the opportunity for advancement in their PA program by improving their individual rapport with students and their organizational skills.
\end{abstract}

Key Words: teaching effectiveness, PA students, PA programs, teaching characteristics 


\section{INTRODUCTION}

The curriculum in physician assistant (PA) programs is fast paced, rigorous, and continually evolving. In addition to being transmitters of knowledge, PA faculty also serve as facilitators of learning and foster the development of critical thinking skills of the PA student. It is important for PA faculty to be aware of the characteristics that make an effective teacher as effective teaching can enhance student learning. ${ }^{1}$

Most faculty members (80.4\%) teaching in PA programs are physician assistants, and they teach $67.4 \%$ of the didactic curriculum. 2,3 PA program faculty members are typically clinicians who have no formal training in education and frequently learn how to teach as they gain experience in the classroom, or they model instructors who they felt were effective teachers. It is frequently assumed that clinical talent translates to educational talent, and an exceedingly small amount of time is spent on preparing PA faculty members for their responsibilities as teachers.

Information regarding teaching effectiveness of PA faculty is often obtained using student evaluations of teaching. While these evaluations are used to give feedback to faculty members regarding their teaching that may be utilized for self-improvement, feedback is also frequently utilized as part of the decision-making process for retention or promotion of faculty members. Recognition of teaching excellence as criteria for promotion as a clinician-educator has gained acceptance in recent years. ${ }^{4}$ In PA programs, student evaluations are not standardized and vary by institution. The evaluations are typically obtained at the end of a course and have students answer a predetermined set of questions to evaluate a faculty member's teaching effectiveness. Other researchers have shown that there are many sources of bias in student evaluations. Biases are observed in regard to

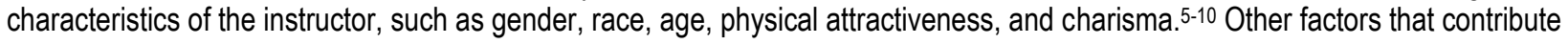
as biases on student evaluations are not under the instructor's control and include classroom environment, class size, class time, and course content. ${ }^{11,12}$ The numerous factors involved make it impossible to adjust student evaluations for bias. ${ }^{10}$ Another constraint of student evaluations is that they can only assess the student experience in a specific course.

Being perceived as an effective educator by the students may have a significant impact on career trajectory for PA faculty. The role that student evaluations play in the assessment of faculty job performance may be one reason that when asked about sources and extent of stress among PA faculty, "students" were reported as a "somewhat" or "extensive" stressor by $70.5 \%$ of respondents in the Physician Assistant Education Association (PAEA) 2015 Faculty and Directors Research Report. ${ }^{2}$

Characteristics of effective teaching have been studied extensively in undergraduate education, especially in the arts; however, there are only a small number of researchers who studied teaching effectiveness conducted in health science programs with many of those involving clinical rather than classroom teaching. The studies conducted in health science programs included students in medicine, dentistry, dental hygiene, physiotherapy and nursing. ${ }^{13-18}$ The methods used to gauge effective teaching in those studies varied and included using a strengths, weaknesses, opportunities, and threats (SWOT) analysis; focus group interviews; ranking or using a Likert scale for a list of given characteristics; evaluation of a narrative; and open-ended questions. ${ }^{13-18}$ Some of the researchers in health science evaluated only the perspective of the student while others compared student and faculty responses. ${ }^{13-18}$ Prior to our study, there were no publications regarding teaching effectiveness in PA programs. The purpose of this study was to identify the characteristics PA students find most important for effective teaching by faculty in PA programs.

\section{METHODS}

We designed a survey instrument after a review of the existing literature. The survey used a qualitative methodology via an openended question: What are the most important qualities or characteristics for PA faculty to possess for effective teaching in a PA program? We designed the survey instrument to avoid the biases associated with student evaluations. The open-ended question was used for the students to answer in their own words rather than choosing an answer option from a list or scale, and the survey question was not linked to a specific course or instructor.

The PA students were able to write a narrative into the text box that followed the open-ended question. Length of the answer of the question was determined solely by the respondents. In addition to answering the posed question, respondents were also asked to indicate their age, gender, and undergraduate academic degree. The survey was distributed via email using Qualtrics Online Survey Software to 322 didactic and clinical year students across 3 PA programs. Prior to recruitment, the research proposal was determined to be exempt by the Institutional Review Board (IRB). The programs surveyed included 2 geographical regions of the country: the West and the South. ${ }^{3}$ Completion of the survey implied consent.

Because students were able to leave a narrative of any length, which could contain more than one phrase or sentence, we wanted a context in which we could place individual thoughts from the students' narrative into categories. We chose Marsh's Students' Evaluation of Educational Quality (SEEQ) instrument as our framework. ${ }^{19}$ Marsh's instrument includes nine major

C The Internet Journal of Allied Health Sciences and Practice, 2018 
teaching behaviors and has been shown to be multidimensional, reliable, valid, and has been replicated across different academic disciplines. ${ }^{20-22}$

Content analysis was used to organize the responses into individual words or phrases and then categorized into one of the 9 factors from Marsh's SEEQ instrument. ${ }^{19,20}$ The classifications as derived by Marsh are learning, enthusiasm, organization, group interaction, individual rapport, breath of coverage, assignments/reading, course difficulty, and examination fairness/grading. To ensure that the responses were categorized into the correct factor, the authors used operational definitions as described by Schönwetter et al. ${ }^{15}$ The decision to use Marsh's SEEQ instrument and the operational definitions described by Schönwetter et al. ${ }^{15}$ were made prior to the start of the research study.

\section{RESULTS}

Eighty-three students completed the survey, resulting in a response rate of $25 \%$. The average number of words in the student narrative was 33.65. After analyzing the content of the student responses and breaking the narrative down into individual words or phrases that completed a thought, there were a total of 304 responses that were placed into one of the 9 SEEQ categories. The average number of thoughts per narrative was 3.66. Descriptive characteristics of the respondents to the survey are shown in Table 1. The most common age group represented was ages 25 to $34(56.6 \%)$. Women represented $65 \%(n=54)$ of respondents while men represented $35 \%(n=29)$. The most common undergraduate academic degree was in the sciences $(n=$ $56,67.5 \%)$.

Table 1. Respondent Demographics

\begin{tabular}{|l|c|c|}
\hline \multicolumn{1}{|c|}{} & Response Category & $n(\%)$ \\
\hline Age & 18 to 24 years & $17(20.5 \%)$ \\
\hline & 25 to 34 & $47(56.6 \%)$ \\
\hline Gender & 35 to 44 & $16(19.3)$ \\
\hline & 45 to 54 & $3(3.6 \%)$ \\
\hline Degree & Male & $29(35 \%)$ \\
\hline & Female & $54(65 \%)$ \\
\hline & Business & $6(7.2 \%)$ \\
\hline & Education & $4(4.8 \%)$ \\
\hline & Oumanities & $7(8.4 \%)$ \\
\hline & Sciences & $1(1.2 \%)$ \\
\hline
\end{tabular}

When categorizing the individual phrases by SEEQ category $(n=304)$, individual rapport $(26.9 \%)$ and organization $(24.9 \%)$ were the most frequent categories represented. Five of the 7 other categories were also represented, and their numbers were learning $(16.7 \%)$, enthusiasm (11.5\%), group interaction (8.5\%), breadth of coverage (8.2\%), and examination fairness/grading (3\%). There were no phrases that corresponded with the assignments/reading $(0 \%)$ or course difficulty $(0 \%)$ categories. The number of responses given for each category is shown in Table 2. Examples of the most common phrases used in each category are listed in Table 3. 
Table 2. Responses Broken Down by SEEQ Category

\begin{tabular}{|l|l|}
\hline SEEQ Category & $n(\%)$ \\
\hline Individual rapport & $82(26.9 \%)$ \\
\hline Organization & $76(24.9 \%)$ \\
\hline Learning & $51(16.7 \%)$ \\
\hline Enthusiasm & $35(11.5 \%)$ \\
\hline Group interaction & $26(8.5 \%)$ \\
\hline Breadth of coverage & $25(8.2 \%)$ \\
\hline Examination fairness/grading & $9(3 \%)$ \\
\hline Assignments/reading & $0(0 \%)$ \\
\hline Course difficulty & $0(0 \%)$ \\
\hline
\end{tabular}

Table 3. Examples of Most Common Phrases Given in each Category

\begin{tabular}{|l|l|}
\hline SEEQ category & Examples of most common responses \\
\hline Individual rapport & Empathy for students \\
\hline & Patience \\
\hline & Ability to relate to students \\
\hline & Availability to students \\
\hline & Approachability \\
\hline & Well organized \\
\hline & Eloquence in speaking \\
\hline & Good communication skills \\
\hline Learning & Consistency \\
\hline & Knowledgeable about subject matter \\
\hline & Clinical or teaching experience \\
\hline Enthusiasm & Teaching to different learning styles \\
\hline & Enthusiasm for teaching \\
\hline & Sense of humor \\
\hline Group interaction & Passion for the profession \\
\hline & Willingness to answer questions \\
\hline & Being open to feedback \\
\hline Breadth of coverage & Posing thoughtful questions to the students \\
\hline & Experience in the topic being taught \\
\hline & Keeping the lectures up to date \\
\hline Examination fairness/grading & Keep the material relevant \\
\hline & Making clear expectations of material to be covered on the test \\
\hline & Fairness in grading \\
\hline
\end{tabular}




\section{DISCUSSION}

Patterns in both the responses given by the PA students and the most common responses given for each category were identified by the results of this qualitative study. The most important quality for PA faculty to possess from the students' perspective was individual rapport $(26.9 \%)$, followed by organization $(24.9 \%)$. The students who participated in this study valued personal over professional characteristics of the faculty in regard to effective teaching. These findings were similar to findings from previous studies conducted in other health science programs in which personal characteristics were valued more than professional characteristics. $14,15,17,18$

The relationship that the student has with the educator includes individual rapport and the interpersonal skills of the educator. Individual rapport behaviors caused students to feel as though the educator cares about their learning and about them as people. ${ }^{22}$ An environment can be created for the student that is less anxiety provoking and more conducive to learning, which could be motivating to the student. ${ }^{13}$ PA faculty members are entrusted to aid PA students in the development of critical-thinking skills. The environment may be more conducive to developing these skills when the student has a good rapport with the faculty member.

The students in this study also reported the organizational skills of the faculty member as an important characteristic needed for effective teaching. When a faculty member is able to provide lecture material that is well organized and he/she possesses good communication skills when delivering the material, it may be easier for the students to follow the lecture, and they will likely retain more information from that lecture. In addition, when students are reviewing lecture materials while studying for a test, they will likely need to spend less time on material that is laid out in an organized fashion, therefore, making the students' study time more efficient.

When analyzing the results by demographics, our respondent pool was reflective of the national pool of PA students. In our study, there were $65 \%$ female and $35 \%$ male respondents. The national average for female PA student enrollees is $71.5 \%$ and $27.6 \%$ for males. ${ }^{3}$ The age of our respondents also closely resembled the average age of matriculants in PA programs across the country. In our study, $56.6 \%$ of the respondents were between 25 to 34 years of age while the national average for age of matriculants is 25.7 years. ${ }^{3}$

There were several limitations to our study. The data collected included responses in narrative form, and there could be a question regarding the placement of the responses into the appropriate category. To combat this problem, we reviewed all responses and agreed upon their categorization. Another limitation of our study was the response rate. Those who did not respond may have answered differently than those who did respond to the survey, potentially altering the results.

While 3 PA programs were surveyed, additional studies should be conducted and the sample size increased to afford better generalizability. Future research could also include comparing the student and faculty perspectives regarding the most important characteristics for effective teaching by PA faculty because the characteristics viewed as most important may differ between the groups.

\section{CONCLUSIONS}

From the students' perspective, the responses of this study indicated that organization and individual rapport are the most important characteristics needed for effective teaching by PA faculty. The individual rapport responses correlated with the idea that students most value a faculty member's ability to have patience, compassion, and approachability. Organization was also viewed as important and that students highly regard faculty members who are able to communicate effectively and present the material in an organized manner.

The findings of this study are important to consider as retention and promotion of faculty are often based in part on their teaching effectiveness. The results of this study present added value about teaching effectiveness from the students' perspective by omitting the course or instructor as variables, which are known sources of bias on student evaluations. By ensuring that characteristics of individual rapport and organization are incorporated into their teaching style, PA faculty members can optimize the learning environment for students and improve their teaching effectiveness.

Institutional support for faculty development designed to improve teaching effectiveness would benefit the university, PA program, and the faculty member. There are numerous instructional methods available and include workshops, seminars, courses, and fellowships. ${ }^{23-25}$ Outcomes of faculty development interventions designed to improve teaching effectiveness in medicine have shown improvements in knowledge, attitudes, and teaching skills of the participants. ${ }^{23}$ By improving the teaching effectiveness of faculty members, student learning can be enriched and the likelihood of retention or promotion could be improved.

(C) The Internet Journal of Allied Health Sciences and Practice, 2018 


\section{REFERENCES}

1. Bulger $S$, Mohr D, Walls R. Stack the deck in favor of your students by using the four aces of effective teaching. J Effective Teaching. 2002;5(2).

2. Physician Assistant Education Association. Physician Assistant Program Faculty and Directors Survey Report, 2015. Washington, DC: PAEA, 2015. doi: 10.17538/fsr2015.001. Available at: http://paeaonline.org/research/pa-program-facultyand-directors-surveyl. Accessed January 16, 2017

3. Physician Assistant Education Association. By the Numbers: Program Report 31. Washington, DC: PAEA, 2016. doi: 0.17538/PS31.2016. Available at: http://paeaonline.org/wp- content/uploads/2016/11/Program-Survey-31.pdf. Accessed January 22, 2017

4. Hatem CJ, Lown BA, Newman LR. The academic health center coming of age: Helping faculty become better teachers and agents of educational change. Acad Med. 2006;81(11):941-4. [PMID: 17065851]

5. MacNell L, Driscoll A, Hunt AN. What's in a name? Exposing gender bias in student ratings of teaching. Innov High Educ. 2015;40(4):291-303.

6. Arbuckle J, Williams BD. Students' perceptions of expressiveness: age and gender effects on teacher evaluations. Sex Roles. 2003;49(9-10):507-16.

7. Shevlin M, Banyard P, Davies M, Griffiths M. The validity of student evaluation of teaching in higher education: love me, love my lectures? Assess Eval High Educ. 2000;25(4):397-405.

8. Riniolo TC, Johnson KC, Sherman TR, Misso JA. Hot or not: do professors perceived as physically attractive receive higher student evaluations? J Gen Psychol. 2006;133(1):19-35. [PMID: 16475667]

9. Hamermesh DS, Parker A. Beauty in the classroom: instructors pulchritude and putative pedagogical productivity. Econ Educ Rev. 2005;24(4):369-76.

10. Boring A, Ottoboni K, Stark PB. Student evaluations of teaching (mostly) do not measure teaching effectiveness. ScienceOpen Res. 2016 1-11. doi:10.14293/S2199- 1006.1.SOREDU.AETBZC.v1

11. Royal KD, Stockdale MR. Are teacher course evaluations biased against faculty that teach quantitative methods courses? Int J Higher Educ. 2015;4(1):217-24.

12. Hill MC, Epps KK. The impact of physical classroom environment on student satisfaction and student evaluation of teaching in the university environment. Acad Educ Leader J. 2010;14(4):65-79.

13. Schiekirka S, Reinhardt D, Heim S, Fabry G, Pukrop T, et al. Student perceptions of evaluation in undergraduate medical education: A qualitative study from one medical school. BMC Med Educ. 2012;12:45-51. [PMID: 22726271]

14. Buchel TL, Edwards FD. Characteristics of effective clinical teachers. Fam Med. 2005;37(1):30-5. [PMID: 15619153]

15. Schönwetter DJ, Lavigne S, Mazurat R, Nazarko O. Students' perceptions of effective classroom and clinical teaching in dental and dental hygiene education. J Dent Educ. 2006;70(6):624-35. [PMID: 16741130]

16. Henzi $D$, Davis $E$, Jasinevicius $R$, Hendricson W. In the students' own words: what are the strengths and weaknesses of the dental school curriculum? J Dent Educ. 2007;71(5):632-45.

17. Cross V. Perceptions of the ideal clinical educator in physiotherapy education. Physiotherapy. 1995;81(9):506-13.

18. Berg CL, Lindseth G. Students' perspectives of effective and ineffective nursing instructors. J Nurs Educ. 2004;43(12):565-8. [PMID: 15620072]

19. Marsh HW, Bailey M. Multidimensional students' evaluations of teaching effectiveness: A profile analysis. J Higher Educ. 1993;64(1):1-18.

20. Marsh HW. Students' evaluations of university teaching: Dimensionality, reliability, validity, potential biases, and utility. J Educ Psychol. 1984;76(5):707-14.

21. Marsh HW. SEEQ: A reliable, valid, and useful instrument for collecting students' evaluations of university teaching. Br J Educ Psychol. 1982;52(1):77-95.

22. Marsh HW, Ware JE. Effects of expressiveness, content coverage, and incentive on multidimensional student rating scales: New interpretations of the Dr. Fox effect. J Educ Psychol. 1982;74(1):126-34.

23. Steinert $Y$, Mann K, Centeno A, Dolmans D, Spencer J, et al. A systematic review of faculty development initiatives designed to improve teaching effectiveness in medical education: BEME Guide No. 8. Med Teach. 2006;28(6):497-526. [PMID: 17074699]

24. Searle NS, Hatem CJ, Perkowski L, Wilkerson L. Why invest in an educational fellowship program? Acad Med. 2006;81(11):936-40. [PMID: 17065850]

25. Hatem CJ, Lown BA, Newman LR. Strategies for creating a faculty fellowship in medical education: Report of a 10-year experience. Acad Med. 2009;84(8):1098-103. [PMID: 19638780] 